with eatgut without drainage, and the foot splinted with a Thomas talipes shoe. The healing was uninterrupted.

Post-operative Treatment.-Daily massage began on June 18, without any passive movements; there was no untoward swelling. Towards the end of July the patient started to move his ankle voluntarily, so passive movements and faradic stimulation were ordered. Voluntary movements were much improved in the beginning of August. On Sept. 1 patient began to walk with light boots, the right one

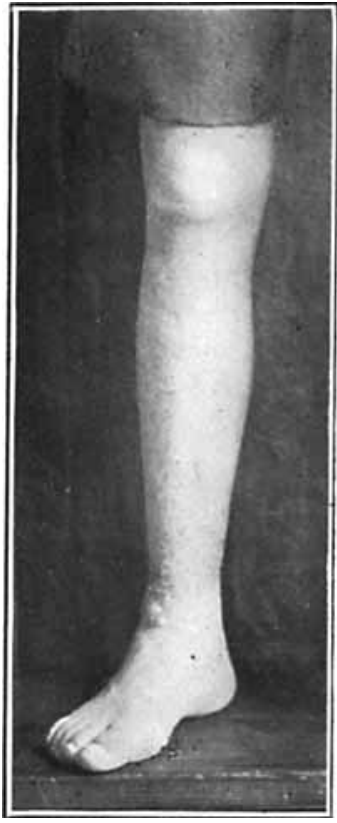

Fia. 137.-Foot after operation. being fitted with an inside iron and outside crook heel and external sole flapper. He walked with crutches for two months, and substituted sticks in November. All movements of the foot and ankle were now free and painless, and the patient could walk for three miles without limp or disability. 'There was no disturbance of circulation whatsoever. (Figs. 137, 138.)

This case is of interest on account of the nutrition of the astragalus. The major part of its blood-supply comes through the sinus tarsi in connection with the interosseous ligament, and one cannot help feeling that these vessels must have been damaged, on account of the ease with which the bone moved on the os calcis.

My thanks are due to Dr. Bayumi, one of my assistants, who has been in charge of the case, and who has supplied me with the notes.

\title{
A CASE OF CONGENITAL ELEVATON OF THE SCAPULA (SPRENGEL'S SHOULDER).
}

\author{
By Captain RaLPH M. de mowbray, R.A.M.C. (T.)
}

In view of the comparative rarity of the above deformity, the following case may be thought worthy of record.

Pte. M., age 21, was admitted to hospital on Feb. 28, 1917, with a gunshot wound of the right shoulder. During the course of examination it was found that the left shoulder was markedly raised as compared with the other side, and that the movements of the scapula on the chest-wall were limited in all directions. The left arm, moreover, could not be raised vertically above the head.

Palpation at once revealed the presence of a bony process running from the vertebral 


\section{RARE OR OBSCURE CASES}

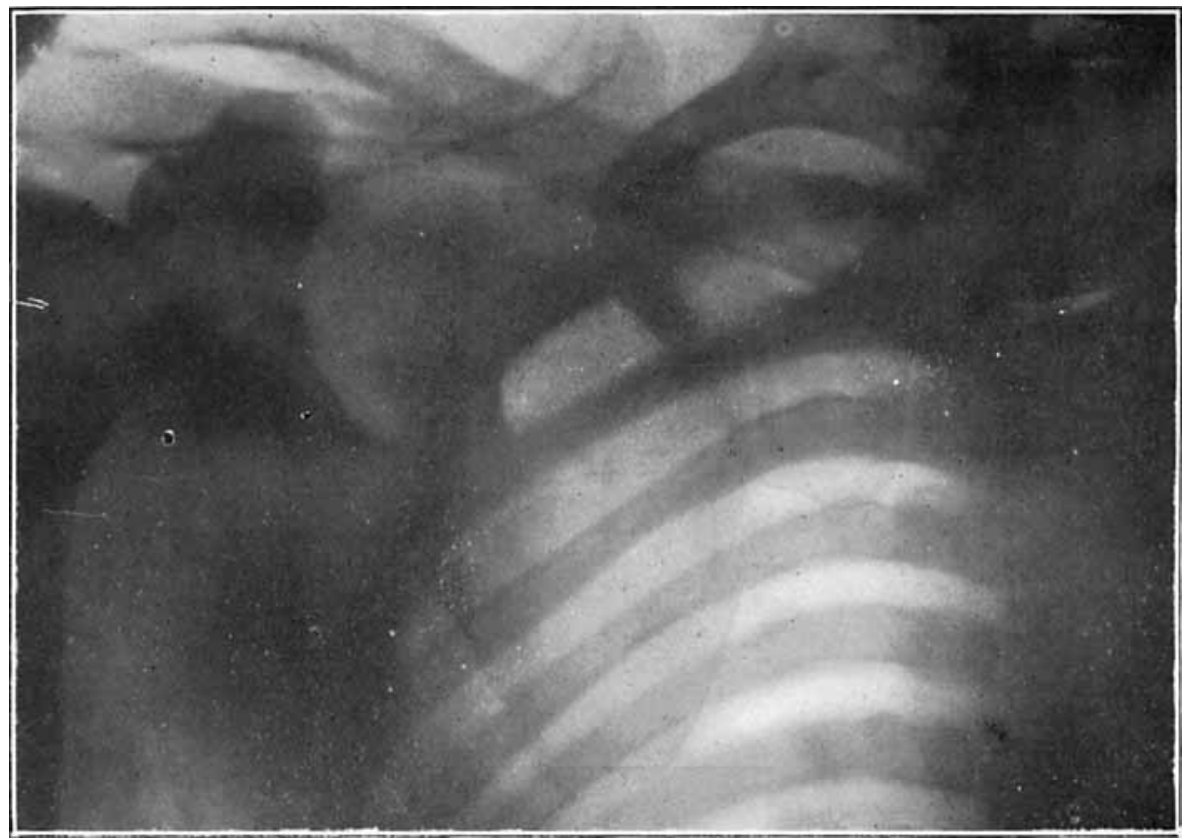

FIG. 139,-Skiagram showing abnormal bone articulating with the sciapula and vertebral columil.

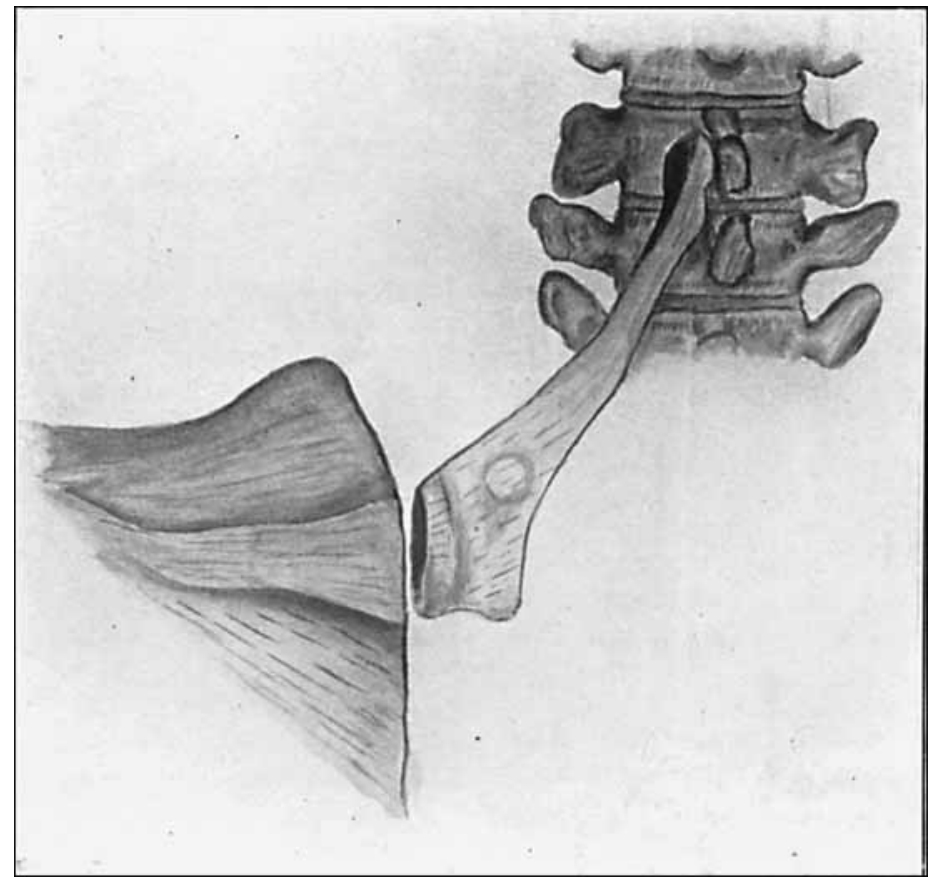

FIG. 140.-Semi-diagrammatic reprezentation of the abnormal bone and its articulations. 


\section{THE BRITISH JOURNAL OF SURGERY}

border of the scapula, at the level of the spine, upwards and inwards towards the spinous process of the seventh cervical vertebra. $\boldsymbol{X}$-ray examination, kindly undertaken by Captain Garfield Evans, showed a well-formed bone, not unlike a clavicle in general appearance, articulating at its outer extremity with the vertebral border of the scapula (Fig. 139). The exact method of attachment of the inner end was, however, difficult to determine, owing to the density of the vertebral bodies.

The patient readily consented to have the bone removed, and this was done on April 6. Superficially the bone was found to be covered by the trapezius muscle, while attached to its deep aspect was a thick muscular belly, apparently a detached portion of the levator anguli scapulæ. As already shown by the $x$-ray plate, a well-formed joint, with an interarticular fibro-cartilage, was present at the outer attachment of the bone, whilst on its inner extremity were two facets, articulating with the lamina and side of the spinous process of the seventh cervical vertebra (Fig. 140). On removal, the bone was found to be $4 \frac{1}{2} \mathrm{in}$. in length, the outer end being broad and flat, while the inner tapered almost to a point.

Professor Shattock, who has kindly interested himself in the case, states that the only clue to the morphology of this condition lies in a cartilaginous bar which occupies a somewhat similar position in a special group of fishes (Dipnoi), the attachments in their case being to the top of the scapula and the occipital region.

It is satisfactory to note that considerable improvement in the movements of the arm at the shoulder-joint and of the scapula on the chest-wall occurred after the removal of the bone.

\section{CONGENITAL ABNORMALITY OF THE WRIST.}

By Captain a. Waldo Connelly, A.A.M.C., and Major holmes a'cotrit, A.A.M.C.

Patient, E. B., is a private in the Australian Imperial Forces, age 17 years 10 months. He enlisted in the Australian Imperial Forces in February, 1916. He did ordinary duty for one month. He was then bugler until his arrival in France in November, 1916. He was ' in the line' on ordinary duty for three months. At this time-that is, in February, 1917-he fell and 'sprained" his right wrist, and states that a swelling appeared on the dorsum. He was then transferred to Divisional Headquarters on account of being under age, and served as batman, although he had difliculty in lifting baggage, etc. The right wrist became more swollen in January, 1918, and he was invalided to hospital.

Family Histony.--The parents are healthy, and there is no history of any abnormality. The patient has three sisters, age 21,15 , and 12 years respectively; all are said to be normal. There are also two brothers, age 13 and 6 years; patient states that his elder brother has 'weak wrists,' exactly like his own, but he believes the younger brother to be normal.

On Examination.- The patient is a fairly well-made youth, 5 feet 4 inches high, and weighing 9 stone. He states that he has always noticed a "weakness oî his wrists, especially the right." Eight years ago his mother took him and his brother to a doctor, on account of "weakness of their wrists, and a hollow over his brother's left wrist." No radiographic examination was made at that time.

At the present time (February, 1918) there is a fluctuating swelling on the dorsal aspect of either wrist, which appears to communicate with the synovial lining of the joint, and can be made to disappear on pressure (Fig. 141). It is apparently a diverticulum or hernial protrusion of the synovial membrane, more marked on the right wrist than on the left. Movements at both joints are unrestricted, except that extension of the right wrist produces pain, and the grip of the right hand is weak.

Radiography (Fig. 142).--Stereoscopic skiagrams were examined, and show :--

Right Wrist.-There are only six carpal bones present. The trapezoid, os magnum, unciform, and pisiform appear to be definitely recognizable. An imperfectly developed bony 